Original Article

\title{
Awareness of Basic Life Support among Health Personnel in a Rural
}

\section{Teaching Hospital}

Pravin Kumar Giri ${ }^{1}$, Bishal Pokhrel ${ }^{2}$, Prem Prasad Panta ${ }^{3}$, Robin Khapung ${ }^{1}$

${ }^{1}$ Assistant Professor, Department of Anesthesiology and Critical Care; ${ }^{2}$ Assistant Professor, Department of Community Medicine and Public Health, ${ }^{3}$ Associate Professor, Department of Community Medicine and Public Health, Karnali Academy of Health Sciences, Jumla

\section{Corresponding Author:}

Dr. Praveen Kumar Giri, E-mail: giripkmd@gmail.com

\begin{abstract}
Background: Cardiopulmonary resuscitation success rates depend on the knowledge and skills of Adult basic life support (BLS) and advanced life support. The objective of the study was to find the level of awareness on BLS and skills among health personnel working in different departments of a rural teaching hospital.

Methods: This descriptive cross-sectional study was conducted in a tertiary care hospital of Karnali Academy of Health Sciences, Jumla, Nepal. The awareness level about BLS was assessed using a structured questionnaire. Health personnel's previous exposure to BLS and the inclusion of BLS in their curriculum was also assessed.
\end{abstract}

Results: Among 91 participants,74\% ( $\mathrm{n}=67)$ heard about BLS ,64\% ( $\mathrm{n}=58)$ have seen performing and $25 \%(n=23)$ have performed CPR. Only 8\%(n=7) attended a workshop on BLS. 43\% $(n=39)$ answered 100 and $46 \%(n=42)$ answered 30 compression per minute in adult during CPR.71\%(n=65) knew the ratio of chest compression to breath in adults. Only $41 \%(n=37)$ identified anatomy/area mid chest for chest compression . Only $40 \%(n=36)$ are familiar to the Heimlich maneuver and $5.5 \%(n=5)$ were aware of the sequence of BLS which is Head tilt , chin lift, check the pulse. Seventy eight percent $(n=71)$ responded that BLS training should be a part of the medical curriculum. Mean awareness of general medicine is significantly lower than other two groups $(\mathrm{P}<0.001)$.

Conclusion: The level of awareness and knowledge regarding BLS is different among health personnel. Hospital staff and nursing students had better knowledge regarding BLS than general medicine students Keywords: Awareness, basic life support (BLS), cardio-pulmonary resuscitation (CPR), Nepal.

\begin{tabular}{|c|c|c|}
\hline \multicolumn{2}{|c|}{ Access this article Online } & ArticleInfo. \\
\hline Quick Response Code & Website: & How to cite this article in Vancouver Style? \\
\hline & www.jkahs.org.np & $\begin{array}{l}\text { Giri PK, Pokhrel B, Panta PP, Khapung R. } \\
\text { Awareness of Basic Life Support among } \\
\text { Health Personnel in a Rural Teaching Hospital } \\
\text { Karnali Academy of Health Sciences } \\
\text { 2020;3(1):1-10. }\end{array}$ \\
\hline & $\begin{array}{l}\text { DOI: } \\
\text { https://doi.org/10.3126/jkahs.v3i1.28834 } \\
\text { The DOI will be functional after the } \\
\text { issue is fully published online as well as } \\
\text { in printed version }\end{array}$ & $\begin{array}{l}\text { Received: } 25 \text { February, } 2020 \\
\text { Accepted: } 28 \text { March, } 2020 \\
\text { Published Online: } 1 \text { April, } 2020 \\
\text { Source of Support: Nil } \\
\text { Conflict of Interest: Nil }\end{array}$ \\
\hline
\end{tabular}




\section{INTRODUCTION}

Basic Life Support includes airway, breathing and circulation support without the use of equipment other than a protective device and the use of an automated external defibrillator (AED).Simple techniques used in the management of choking (foreign body airway obstruction) are also included. ${ }^{1}$ Lifethreatening emergencies can occur anytime and anywhere like the emergency department, during procedures or operations. The most urgent of all is cardiopulmonary arrest. ${ }^{2,3}$ The lack of training and incompetence to deal with these emergencies can have tragic and legal consequences. All students and staff should be aware of basic life support maneuvers. Periodically different organization updates on Cardiopulmonary Resuscitation (CPR) which includes, how to provide basic and advanced cardiac life support to resuscitate valuable lives. ${ }^{4}$ The knowledge of Basic Life Support and practice of simple Cardiopulmonary Resuscitation techniques help the survival of the patient till experienced medical help arrives and in most cases is itself sufficient for survival. 5,6 CPR is a simple and effective procedure if the skill required is maintained by frequent training. All healthcare professionals are expected to have updated knowledge of BLS and CPR guidelines to revive cardiac arrest patients. There are no strictly adapted licensing protocols in Nepal and like other developing countries that mandate health professionals to be trained in current BLS and CPR guidelines.
Karnali province has underdeveloped hilly regions situated in remote mid-western of Nepal. A large number of population is deprived of health facilities in this region due to various demographic factors. Karnali Academy of Health Sciences (KAHS) was established by the Constituent Assembly in the capacity of the Legislature-Parliament under Article 83 of the Interim Constitution 2067 (2007) of Nepal. ${ }^{7}$ The mission and vision of KAHS is to provide the health services in this areas, to facilitate high standard medical education and research activities, to produce skilled human resources to provide health services to the general public by strengthening health services. It is believed that KAHS can fulfill the gap in this underdeveloped and underprivileged region of Nepal. Public expectations from healthcare professionals in medical care are very high. Studies of BLS/ACLS knowledge among health personnel who are at the frontline of medical care are lacking in Nepal. There is a lack of such studies from Karnali region. Hence, the assessment of BLS knowledge among frontline emergency health care providers is needful. The objective of this study is to assess the current knowledge of BLS guidelines among the health personnel. The rational of the study is to identify the gap in the delivery of knowledge and skill and to make a protocol for the institute for mandatory participation in BLS course, refresher course and implement regular drilling to uplift the skill. 


\section{MATERIALS AND METHODS}

\section{Study site and population}

This was a cross-sectional study conducted from December 2019 to February 2020 in Teaching Hospital of Karnali Academy of Health Sciences, Jumla, Nepal. Written informed consent was obtained from each participants. Certificate level nursing and general health students studying in their last year and hospital staffs were the study participants. Hospital staff in this study means health assistant(HA) and staff nurse (SN). Total of 91 healthcare professionals completed the questionnaire and were included for analysis. Among them, 72 students and 19 paramedical staff studying and working in a teaching hospital of Karnali Academy of Health Sciences, Jumla were included. Census sampling was done. All paramedical staff who were working and available at the time of data collection were included. Persons who refused or absent during study period were excluded.

\section{Study Tool}

A self-administered structured questionnaire with multiple-choice questions on BLS was used. Study tool developed was based on American Heart Association 2015 guidelines. Pretest of structured questionnaire to maintain reliability and validity was done among students and paramedical staff from different departments working in the same institution

\section{Data Collection}

Data was collected from study participants by investigator from their respective workplaces after written informed consent. The personal identity of participants in any manner was not disclosed. Researcher tried to minimize any bias in answering the questionnaire, discussions among participants were not permitted and equal time was given to all participants. Clear instructions as to certain questions requiring multiple answers were also provided during the whole procedure. Data were entered using Microsoft excel software then analyzed using SPSS 16.0 .Frequency distribution table and mean was used as descriptive statistics, whereas ANOVA test was performed to compare the mean of respondents as a inferential statistics. $\mathrm{P}$ value $<0.05$ was used for statically significance

\section{RESULTS}

There were 91 participations in this study. Among them, 72 were students and 19 were hospital staff working in a teaching hospital of Karnali Academy of Health Sciences, Jumla. There were $74 \%$ ( $n=67)$ participants who had heard about BLS and CPR in the past. Also, $82 \%(n=75)$ felt that it is useful to know about BLS. Majority of the participants78\% $(n=71)$ responded that BLS training should be in their curriculum. Only $8 \%(n=7)$ think BLS should be done only in hospital settings. About 92\% $(n=84)$ think that their knowledge about BLS was not adequate because of lack of 
professional training. Around 26\% $(\mathrm{n}=24)$ of them heard about ATLS before. Among them, only $64 \%(n=58)$ participants have seen BLS being performed and only $25 \%(n=23)$ have performed CPR on a patient. Only $8 \%(n=7)$ attended a workshop on BLS. About 43\% $(n=39)$ answered that there is 100 chest compressions per minute in the adult during CPR where as $46 \%$ of participants answered only 30 chest compressions per minute.
Around 71\% participants know the right ratio of chest compression to breath in adults. Only $41 \%$ indicated the right location for chest compression that is mid-chest. On basic airway management, only 5\% could arrange head tilt, chin lift, and check pulse in orderly sequence. About $40 \%$ were familiar with Heimlich maneuver. And, 37\% participants rated themselves average on BLS knowledge and 83\% think that BLS knowledge is useful.

Table 1: Questionnaire with participant awareness on BLS

\begin{tabular}{|c|c|c|}
\hline Statement & Yes $n(\%)$ & No n(\%) \\
\hline Have you heard about BLS? & $67(73.63 \%)$ & $24(26.37 \%)$ \\
\hline Do you think that all staff/student need to know about BLS? & $75(82.4 \%)$ & $16(17.6 \%)$ \\
\hline Do you think BLS training should be part of your medical curriculum? & $71(78 \%)$ & $20(22 \%)$ \\
\hline Do you think BLS should be done only in hospital settings? & $7(7.7 \%)$ & $84(92.3 \%)$ \\
\hline Have you heard about BTLS & $24(26.4 \%)$ & $67(73.6 \%)$ \\
\hline Have you ever seen a BLS (CPR) being done? & $58(63.7 \%)$ & $33(36.3 \%)$ \\
\hline Have you ever done a BLS (CPR) on a patient? & $23(25.3 \%)$ & $68(74.7 \%)$ \\
\hline Have you ever attended a workshop on BLS? & $7(7.7 \%)$ & $84(92.3 \%)$ \\
\hline Have you heard of Heimlich maneuver? & $36(39.6 \%)$ & $55(60.4)$ \\
\hline
\end{tabular}

Table 2: Questionnaire with participant knowledge on BLS

\begin{tabular}{|c|c|}
\hline Statement & Answer (\%) \\
\hline $\begin{array}{l}\text { How many chest compressions to be done in one minute in an adult? } \\
100 \\
200 \\
50 \\
30\end{array}$ & $\begin{array}{l}39(42.9 \%) \\
7(7.7 \%) \\
3(3.3 \%) \\
42(46.2 \%)\end{array}$ \\
\hline $\begin{array}{l}\text { What is the ratio of chest compression to breath in adult ? } \\
15: 2 \\
3: 2 \\
30: 2 \\
100: 2\end{array}$ & $\begin{array}{l}4(4.4 \%) \\
15(16.5 \%) \\
65(71.4 \%) \\
7(7.7 \%)\end{array}$ \\
\hline $\begin{array}{l}\text { Please indicate the location for chest compression? } \\
\text { Lt side of chest } \\
\text { Rt side of chest } \\
\text { Mid chest } \\
\text { Xiphisternum }\end{array}$ & $\begin{array}{l}15(16.5 \%) \\
14(15.4 \%) \\
37(40.7 \%) \\
25(27.5 \%)\end{array}$ \\
\hline $\begin{array}{l}\text { Arrange them in orderly sequence } \\
\text { A } \\
\text { ABC } \\
\text { B } \\
\text { C } \\
\text { CAB }\end{array}$ & $\begin{array}{l}4(4.4 \%) \\
5(5.5 \%) \\
2(2.2 \%) \\
45(49.5 \%) \\
24(26.4 \%)\end{array}$ \\
\hline $\begin{array}{l}\text { Please rate yourself on BLS Knowledge } \\
\text { Poor }\end{array}$ & $11(12.1 \%)$ \\
\hline
\end{tabular}




\begin{tabular}{l|l} 
Below average & $16(17.6 \%)$ \\
Average & $34(37.4 \%)$ \\
Good & $26(28.6 \%)$ \\
Excellent & $4(4.4 \%)$ \\
\hline Please indicate the reason for lack of knowledge about BLS & \\
Busy curriculum & $4(4.4 \%)$ \\
Lack of interest & $3(3.3 \%)$ \\
No professional training & $84(92.3 \%)$
\end{tabular}

Further we compared among all participants, where almost all of hospital staff $100 \%(n=19)$ and nursing students $97 \%(n=39)$ knows about BLS but only a quarter of general medicine students $28 \%(n=9)$ know about it. Almost all hospital staff 100\% $(n=19), 95 \%(n=38)$ and $44 \%(n=14)$ agreed that BLS should part of their curriculum and $16 \%(n=3)$ staffs, $2.5 \%(n=1)$ nursing students and 9\%(n=3) general medicine students think that BLS should be done only in hospital setting. Most of nursing student $97.5 \%(n=39)$ and staffs $74 \%(n=14)$ have seen but $42 \%(n=8)$ staffs, $25 \%(n=10)$ and $16 \%(n=5)$ of them performed on a patient.

Table 3: Awareness status among participant about BLS

\begin{tabular}{|c|c|c|c|}
\hline SN & Statement & Yes & No \\
\hline 1 & $\begin{array}{l}\text { Have you heard about BLS? } \\
\text { Hospital Staff } \\
\text { Nursing Student } \\
\text { General Medicine Student }\end{array}$ & $\begin{array}{l}19(100 \%) \\
39(97.5 \%) \\
9(28.1 \%)\end{array}$ & $\begin{array}{l}0(0 \%) \\
1(2.5 \%) \\
23(71.9 \%)\end{array}$ \\
\hline 3 & $\begin{array}{l}\text { Do you think BLS training should be part of your medical curriculum? } \\
\text { Hospital Staff } \\
\text { Nursing Student } \\
\text { General Medicine Student }\end{array}$ & $\begin{array}{l}19(100 \%) \\
38(95 \%) \\
14(43.8)\end{array}$ & $\begin{array}{l}0(0 \%) \\
2(5 \%) \\
18(56.8 \%)\end{array}$ \\
\hline 4 & $\begin{array}{l}\text { Do you think BLS should be done only in hospital settings? } \\
\text { Hospital Staff } \\
\text { Nursing Student } \\
\text { General Medicine Student }\end{array}$ & $\begin{array}{l}3(15.8 \%) \\
1(2.5 \%) \\
3(9.4 \%)\end{array}$ & $\begin{array}{l}16(84.2 \%) \\
39(97.5 \%) \\
29(90.6 \%)\end{array}$ \\
\hline 7 & $\begin{array}{l}\text { Have you ever seen a BLS (CPR) being done? } \\
\text { Hospital Staff } \\
\text { Nursing Student } \\
\text { General Medicine Student }\end{array}$ & $\begin{array}{l}14(73.7 \%) \\
39(97.5 \%) \\
5(15.6)\end{array}$ & $\begin{array}{l}5(26.3 \%) \\
1(2.5 \%) \\
27(84.4 \%()\end{array}$ \\
\hline 8 & $\begin{array}{l}\text { Have you ever done a BLS (CPR) on a patient? } \\
\text { Hospital Staff } \\
\text { Nursing Student } \\
\text { General Medicine Student }\end{array}$ & $\begin{array}{l}8(42.1 \%) \\
10(25 \%) \\
5(15.6 \%)\end{array}$ & $\begin{array}{l}11(57.9 \%) \\
30(75 \%) \\
27(84.4 \%)\end{array}$ \\
\hline
\end{tabular}

Among them 89.5\% ( $\mathrm{n}=17)$ hospital staff, 7.5\% $(\mathrm{n}=3)$ and 59\% $(\mathrm{n}=19)$ replied right answer of chest compression during CPR. Almost all staff 100\% $(n=19), 92.5 \%(n=37)$ nursing students and only 28\% $(n=9)$ general medicine students have knowledge about chest compression to breath ratio. Only $21 \%(n=4)$ staff, $62.5 \%(n=25)$ nursing student and $25 \%(n=8)$ general medicine students can locate right location for chest compression. While only $26 \%(n=5)$ of hospital staff and none of student have knowledge about basic airway management. Very few of general medicine student $6 \%(n=2)$, half of hospital staff 63\% (n=12) and nursing student 55\% (n=22) know about Heimlich maneuver. 
Table 4: Knowledge about BLS among participants

\begin{tabular}{|c|c|c|}
\hline Statement & Right & Wrong \\
\hline $\begin{array}{l}\text { Indicate the number of compressions to be done in one minute in an adult? } \\
\text { Hospital Staff } \\
\text { Nursing Student } \\
\text { General Medicine Student }\end{array}$ & $\begin{array}{l}17(89.5 \%) \\
3(7.5 \%) \\
19(59.4 \%)\end{array}$ & $\begin{array}{l}2(10.5 \%) \\
37(92.5 \%) \\
13(39.6 \%)\end{array}$ \\
\hline $\begin{array}{l}\text { Mark the ratio of chest compression to breath in adults? } \\
\text { Hospital Staff } \\
\text { Nursing Student } \\
\text { General Medicine Student }\end{array}$ & $\begin{array}{l}19(100 \%) \\
37(92.5 \%) \\
9(28.1 \%)\end{array}$ & $\begin{array}{l}0(0 \%) \\
3(7.5 \%) \\
23(71.9 \%)\end{array}$ \\
\hline $\begin{array}{l}\text { Please indicate the location for chest compressions? } \\
\text { Hospital Staff } \\
\text { Nursing Student } \\
\text { General Medicine Student }\end{array}$ & $\begin{array}{l}4(21.1 \%) \\
25(62.5 \%) \\
8(25 \%)\end{array}$ & $\begin{array}{l}15(78.9 \%) \\
15(37.5 \%) \\
18(75 \%)\end{array}$ \\
\hline $\begin{array}{l}\text { Arrange them in orderly sequence. } \\
\text { Hospital Staff } \\
\text { Nursing Student } \\
\text { General Medicine Student }\end{array}$ & $\begin{array}{l}5(26.3 \%) \\
0(0 \%) \\
0(0 \%)\end{array}$ & $\begin{array}{l}14(73.7 \%) \\
40(100 \%) \\
32(100 \%)\end{array}$ \\
\hline $\begin{array}{l}\text { Have you heard of Heimlich maneuver? } \\
\text { Hospital Staff } \\
\text { Nursing Student } \\
\text { General Medicine Student }\end{array}$ & $\begin{array}{l}12(63.2 \%) \\
22(55 \%) \\
2(6.3 \%)\end{array}$ & $\begin{array}{l}7(36.8 \%) \\
18(45 \%) \\
30(93.8 \%)\end{array}$ \\
\hline
\end{tabular}

Awareness and knowledge was given as total of 14 score. While analyzing the highest mean score was in hospital staff (10.15 \pm 1.7$)$,followed by Nursing students( $9.05 \pm 1.5)$ and general medicine students (4.6 \pm 2.5$)$.The mean knowledge score of hospital staff and nursing students is significantly higher than the general medicine students $(\mathrm{P}<0.001)$.

Table 5: Comparison of BLS score

\begin{tabular}{|l|r|r|r|r|r|r|}
\hline Program & Frequency & Mean & SD & Minimum & Maximum & p-value \\
\hline Hospital Staff & 19 & 10.15 & 1.70 & 7.00 & 12.00 & $<.001$ \\
\hline Nursing students & 40 & 9.05 & 1.58 & 6.00 & 13.00 & 10.00 \\
\hline General Medicine Students & 32 & 4.62 & 2.57 & 0.00 & 13.00 \\
\hline Total & 91 & 7.72 & 3.06 & 0.00 & \\
\hline
\end{tabular}

\section{DISCUSSION}

The study was done to assess the level of knowledge regarding BLS among Certificate level nursing and General health students studying in their last year and hospital staffs in Karnali Academy of Health Science, Jumla. Among participants, Majority had heard about BLS in the past and felt that it is useful to know about BLS. Similarly most of the participants responded that BLS training should be in their curriculum. But, there were participants (8\%) who think that BLS should be done only in hospital settings. It was observed (92\%) that limited knowledge of BLS was due to lack of professional training. It was found in this study that majority of participants (64\%) have seen BLS being performed but only one fourth of them have performed CPR on a patient. There 
were meager (only 8\%) number of participants who had attended a workshop on BLS. Around half of the participants did not answer the correct rate of chest compressions during CPR. But, most of them (71\%) know the right ratio of chest compression to ventilation. Majority of the participants do not know the right location for chest compression. There was clear lack of knowledge on basic airway management among participants. Around one third of the participants rated that they are average on BLS knowledge. But most of them admitted that BLS knowledge is useful.

In 2010, Chadra shekharan S performed a study among medical, dental, nursing students and doctors, where they found that awareness of Basic Life Support (BLS) among them was very poor. ${ }^{8}$ Similarly, $\mathrm{N}$ Baduni et al. conducted a study among dental practitioners in 2014 suggesting that dental practitioners also need BLS training, emergency resuscitation equipment and drugs. ${ }^{9}$ In consistent to our study, Aroor A et al. in 2014 conducted a study among students in a tertiary care hospital in South India. They concluded that the awareness level regarding BLS among medical, dental, nursing students, intern and resident doctors was below average. ${ }^{10}$ Another study performed by al Enizi BA et al. in 2016 among non-health personnel (secondary school teachers) concluded that have a low level of knowledge and skills regarding basic life support techniques, specifically CPR. ${ }^{11}$ Nambiar M. et al in 2016 conducted a study amongst healthcare professionals of south India, where they found a low level of knowledge on BLS and ACLS among healthcare workers. ${ }^{12}$ Similar findings was reported by Irfan B. et al. from Pakistan in 2019. ${ }^{13}$ Hospital staffs and nursing students have significantly higher awareness and knowledge in comparison of general medicine students. Hospital staff and nursing students are directly involved in inpatient care but general medicine students had less opportunity, which may be the cause of this disparity on awareness and knowledge. There are certain limitations on this study. It was a single center study with limited sample size. There are mixed participants of staff who were working in hospital and students who were still studying, which may have caused some mixed response.

\section{CONCLUSION}

The level of awareness and knowledge regarding BLS is different among health personnel. Hospital staff and nursing students had better knowledge regarding BLS than general medicine students. Hence, BLS and other resuscitation skills should be a part of the every curriculum and students should master the skills during their studies.

Acknowledgment: I would like to thank Dr. Niresh Thapa for his support during this study and all the participants for their valuable participation. 


\section{REFERENCE}

1. Soar J, Nolan JP, Böttiger BW, Perkins GD, Lott C, Carli P, et al. European Resuscitation Council Guidelines for Resuscitation 2015. Section 3. Adult advanced life support. Resuscitation 2015(95):100-47. Google Scholar |PubMed | Full Text | CrossRef

2. Brahams D. Death in the Dentist's Chair. The Lancet 1989 Oct 21;2(8669):991-2.. Google Scholar | PubMed | Full Text | CrossRef

3. Chapman PJ. Medical emergencies in dental practice and choice of emergency drugs and equipment: A survey of Australian dentists. Australian Dental Journal 1997 4:42:2. Google Scholar $\mid$ PubMed $\mid$ Full Text $\mid$ CrossRef

4. American Heart Association. Guidelines 2015 CPR \& ECC. Circulation 2015 30(5): 223-231. CrossRef $\mid$ Full Text

5. Steen PA, Kramer-Johansen J. Improving cardiopulmonary resuscitation quality to ensure survival. Current Opinion in Critical Care 2008 7 :14(3):299-304. CrossRef | Google Scholar | PubMed, Full Text

6. Meaney PA, Bobrow BJ, Mancini ME, Christenson J, de Caen AR, Bhanji F, et al. Cardiopulmonary resuscitation quality: Improving cardiac resuscitation outcomes both inside and outside the hospital: A consensus statement from the American heart association. Circulation 2013 7(128)4. CrossRef | Google $\underline{\text { Scholar, PubMed } \mid \text { Full Text }}$

7. Karnali Academy of Health Sciences Act, 2068 (2011) Mar-Apr; 54(2): 121-126 -Law Commission [Internet].[cited 2020 Apr 13]. Full Text

8. Chandrasekaran S, Kumar S, Bhat SA, kumar S, Shabbir PM, Chandrasekaran VP.

Awareness of basic life support among medical, dental, nursing students and doctors. Indian Journal of Anaesthesia 2010 3-4: 54(2): 121-126.. CrossRef | Google Scholar | PubMed $\mid$ PMC $\mid$ Full Text

9. Baduni N, Prakash P, Srivastava D, Sanwal M, Singh B. Awareness of basic life support among dental practitioners. National Journal of Maxillofacial Surgery 2014 1-7: 5(1): 19-22. CrossRef | Google Scholar | PubMed | PMC | Full Text

10. Aroor AR, Saya RP, Attar NR, Saya GK, Ravinanthanan M. Awareness about basic life support and emergency medical services and its associated factors among students in a tertiary care hospital in South India. Journal of Emergencies, Trauma and Shock 2014 7-8: 7(3): 166-169. CrossRef | Google Scholar | PubMed $\mid$ Full Text

11. Enizi BA, Saquib N, Zaghloul MSA. Knowledge and Attitudes about Basic Life Support among Secondary School Teachers in Al-Qassim, Saudi Arabia. International Journal of Health Sciences 2016 7: 10(3): 415422.CrossRef | Google Scholar | PubMed | PMC $\mid \underline{\text { Full Text }}$

12. Nambiar M. Is current training in basic and advanced cardiac life support (BLS and ACLS) effective? A study of BLS and ACLS knowledge amongst healthcare professionals of North- Kerala. World Journal of Emergency Medicine 2016 7(4):263-269. CrossRef | Google Scholar, PubMed | PMC | Full Text

13. Irfan B, Zahid I, Khan MS, Khan OAA, Zaidi $S$, Awan S, et al. Current state of knowledge of basic life support in health professionals of the largest city in Pakistan: a cross-sectional study. BMC Health Services Research 2019;19:865 .

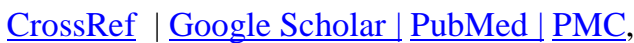
Full Text 